\title{
Pavlovian phenomena in conditioned acceleration: Spontaneous recovery
}

\author{
DAVE RIESS \\ Galesburg State Research Hospital, Galesburg, Ill. 61401
}

Two experiments studied the course of spontaneous recovery of conditioned acceleration. Experiment 1 first showed that extinction of conditioned acceleration is essentially a discontinuous process, with little decline in the inflection ratios across sessions until the occurrence of an abrupt drop to normal avoidance rates during the CS. Spontaneous recovery was demonstrated at 7-day intervals for 5 weeks and at $24-\mathrm{h}$ intervals for an additional week. In Experiment 2, recovery was demonstrated at a 1-month interval after extinction. It was also shown that two extinguished CSs in compound retained their additive summation property during spontaneous recovery.

Spontaneous recovery occupies a unique status in American experimental psychology. Of all of the major phenomena bequeathed by Pavlov (1960) to several generations of American psychologists interested in the conditioning process, spontaneous recovery has been by far the most unanimously ignored. The reason for this relative neglect is presumably the "atheoretical" nature of spontaneous recovery. As an experimental phenomenon, it generated no differential predictions capable of testing the major theories of learning which dominated nearly all the conditioning research of American experimental psychologists in the 20-year era when the grand behavior systems flourished and competed to establish a single all-encompassing theory of learning. Although the grand theoretical systems themselves have long since languished and passed into history, the hierarchy of experimental importance and investigative priorities assigned to various paradigms and variables during this period has outlived the theories which sired it, and spontaneous recovery continues to suffer its earlier neglect. While some early studies (Ellson, 1938; Lewis, 1956) were concerned with the phenomenon in appetitive behavior, not a single study dealing with spontaneous recovery in aversive classical conditioning could be found by the author in the English literature, and the topic is not even listed in the Psychological Abstracts. In the corresponding period, studies of other phenomena in both classical and operant types of aversive control have produced an enormous literature on dis crimination, st imulus generalization, and extinction.

The present two studies attempt to trace the course of spontaneous recovery of an aversive Pavlovian CR. The "conditioned response" used here was increases in response rates elicited by the presentation of a Pavlovian CS+ during avoidance behavior (conditioned acceleration). The precise rationale for considering such avoidance increases to constitute conditioned responses is contained in previous reports (Riess, 1969, 1970). Although spontaneous recovery has never been studied in conditioned acceleration, retention of an unextinguished aversive $\mathrm{CR}$ has been shown in conditioned suppression over periods of time up to 5 years (Hoffman, Fleshler, \& Jensen, 1963; Hoffman, Selekman, \& Fleshler, 1966). Also, the extinction data reported in Experiment 1 are new, although Weisman \& Litner (1969) have demonstrated forgetting (the decline in an unextinguished $C R$ as a simple function of passage of time) in conditioned acceleration, and Martin \& Riess (1969) found resistance to forgetting monotonically related to UCS intensity in the same paradigm.

EXPERIMENT 1: EXTINCTION AND SPONTANEOUS RECOVERY Subjects

The Ss were four naive female Wistar albinos taken from the colony maintained by the Galesburg State Research Hospital Psychology Department. They were between 72 and 82 days of age when they were moved to individual cages for the start of this experiment.

Apparatus

The apparatus consisted of a modified Lehigh-Valley shuttlebox, a shock generator, scrambler, white-noise generator, air fan, and sound-attenuation chest described in detail previously (Riess \& Bath, 1970, Experiment 2). Two 60-W red lights in either side of the sound chest ceiling served as the CS.

\section{Procedure}

All four Ss were run through the following sequence of treatments:

(1) Hurdle cross acquisition consisted of 13 daily $1 / 2$-h sessions of Sidman avoidance at $\mathrm{RS}=30, \mathrm{SS}=5$, and shock $=.2 \mathrm{sec}, 1.6 \mathrm{~mA}$.

(2) Adaptation was identical to Step 1 except that 30 -sec red light presentations occurred at the start of the 10th, 15th, 20th, 25th, and 30th min of each session. Although the light was unreinforced, the avoidance contingencies remained in effect. A daily conditioned inflection ratio was computed from the formula $\mathrm{CIR}=2 \mathrm{~B} /(\mathrm{A}+2 \mathrm{~B})$, where $\mathrm{A}=$ responses during the $1 \mathrm{~min}$ preceding the light and $B=$ responding during the light. This was continued until each $\mathrm{S}$ met an adaptation criterion of two consecutive sessions with the CIR between .475 and .525 for all 10 presentations.

(3a) Classical conditioning consisted of eight coterminous light-shock pairings given every other day while $S$ was confined to one side of the shuttlebox by a plastic barrier. The side of confinement was alternated on successive sessions. The CS-US interval was a VI 15-sec schedule with two values each of $5,10,15$, and $30 \mathrm{sec}$. The ITI was a VI 90 -sec schedule with three values of 60 and $120 \mathrm{sec}$ and two values of $90 \mathrm{sec}$. The UCS was a 1 -sec 3-mA shock.

(3b) Testing was identical to Step 2 , began the day following the second classical conditioning session, and was continued for three sessions. Step 3a was continued on alternate days.

(4a) Pavlovian extinction was identical to Step 3a, except that the light went unreinforced.

(4b) Extinction testing was identical to Step 2 and continued on days following $4 \mathrm{a}$ until each $S$ met an extinction criterion identical to that for adaptation.

(5a) Avoidance was identical to Step 1 and was conducted every day for 5 weeks, except the day on which each $\mathbf{S}$ met the extinction criterion.

(5b) Spontaneous recovery testing was identical to Step 2 and was conducted at weekly intervals (spaced condition) following extinction for 5 weeks. A 6 th week with all five sessions devoted to testing (massed condition) completed the experiment. Results

The results are presented in Fig. 1. The adaptation criterion was reached in the first 2 days by three Ss and in 3 days by $S 39$. The mean CIR on the first adaptation day was only .450 and was below .500 in all four $\mathrm{Ss}$, indicating that the unconditioned effects of the visual stimulus were suppressive and that the red light was an external inhibitor of avoidance behavior. Since this is a somewhat unusual result for superimposing a novel stimulus on an avoidance baseline, a more detailed look at the first day of adaptation was indicated. The shock rate during all light on responding was found to be .8 shocks/min, and the same rate for all light-off responding was .12 


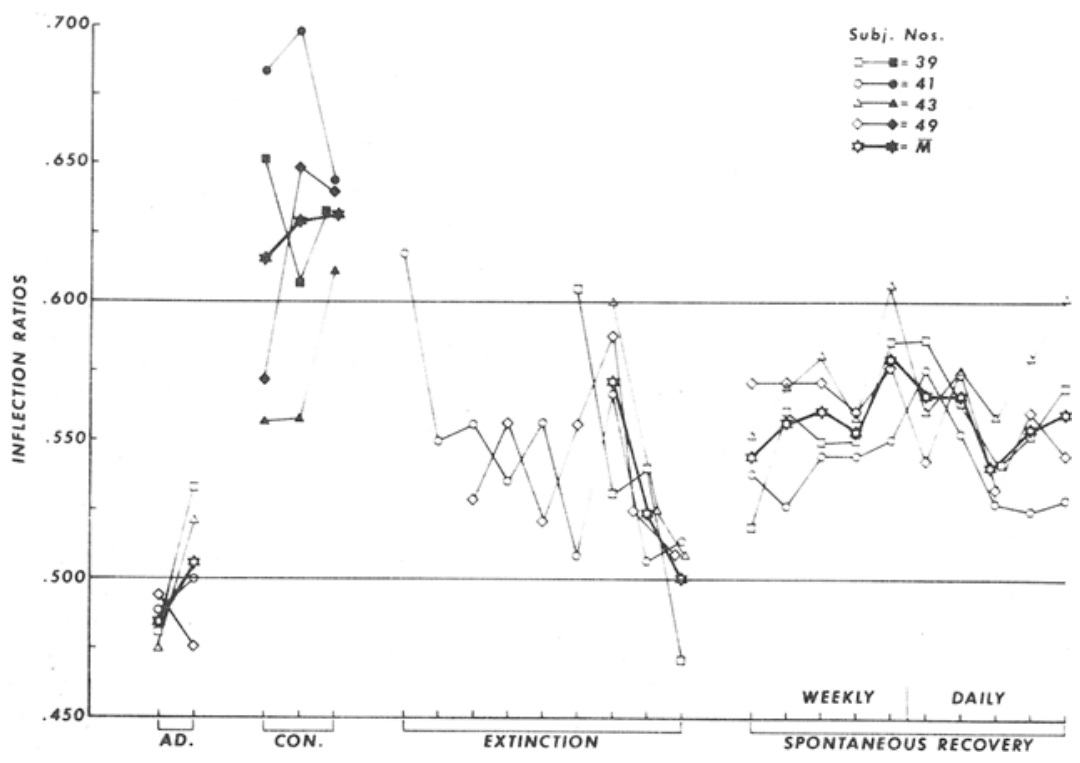

Fig. 1. Conditioned inflection ratios for adaptation (last 2 days only), conditioning (CON), extinction (presented as a "backwards" curve), and spontaneous recovery. .500 indicates no change in rate and .600 indicates a $50 \%$ increase in rate.

shocks/min. Translated into a pro rata CIR for shocks, this yields a ratio of .878 , or about a $700 \%$ increase in shocks during the novel stimulus. Compared with previous results for adaptation in which either response acceleration or no change has been routinely obtained, two differences between the present results and earlier ones emerge: (1) the CS was a red light in the present study and a white light in previous ones; and (2) the Ss were female in the present study and males in previous studies. Unfortunately, nothing in the present results suggests which of these two variables was responsible for the differences in adaptation, but the suppressive effect of the novel stimulus in this study appears to merit follow-up.

Returning to the major results, Fig. 1 shows that following separate pairing with shock, the light produced about a $65 \%$ increase in avoidance rates (CON) during testing. Following separate unreinforced light presentations, the CIRs dropped to criterion extinction range in Sessions 3-9. The extinction data are plotted as a "backwards" curve (Hays, 1953) because there is little change in the individual CIRs during extinction prior to the abrupt drop to the criterion range. Recovery of conditioned acceleration occurred at all five intervals under the spaced (weekly) test procedure but only to about $50 \%$ of the original CR. This level was maintained, however, throughout the five additional sessions of the massed (daily) testing. Both of these results were somewhat unexpected in that the spaced recovery condition was expected to produce levels of recovery more nearly comparable to conditioning and the massed condition was expected to produce a very gradual drop toward $\mathbf{5 0 0}$.

\section{EXPERIMENT 2: STIMULUS SUMMATION IN SPONTANEOUS RECOVERY Subjects}

The Ss were three holdovers from an experiment on stimulus summation, and their detailed histories are available there (Riess, 1969). Briefly, these involved avoidance acquisition and classical conditioning of fear CRs to a 60-W light stimulus and an 87-dB tone. The fourth $S$ in the summation study was not included because of failure to extinguish in the allotted 7 days.

\section{Apparatus}

The apparatus was a modified Miller-Mowrer shuttlebox, a shock generator, and scrambler described in detail previously (Riess, 1969).

\section{Procedure}

Only the last 10 sessions of the summation experiment are relevant to the data presented here and will be described as Steps 1 and 2. The four steps in order were:

(1) Testing of the excitatory properties of the two fear CSs was conducted in a two-component respondent-operant multiple schedule, with classical conditioning followed by avoidance in the same sessions.
In the first (respondent) component, eight coterminous CS-shock pairings were administered. The CS was either a $60 \cdot \mathrm{W}$ light (four reinforcements) or an $87-\mathrm{dB} 1,000 \cdot \mathrm{Hz}$ tone (four reinforcements) in a randomized order. The CS-US interval was variable (VI $16 \mathrm{sec}$ ), with values of $5 \mathrm{sec}(2), 10 \mathrm{sec}(1), 15 \mathrm{sec}(2), 20 \mathrm{sec}$ (1), and $30 \mathrm{sec}(2)$. The UCS was a 5-sec 2-mA shock. The intertrial interval (ITI) was also variable (VI $90 \mathrm{sec}$ ), with values of $60 \mathrm{sec}(2)$, $75 \mathrm{sec}(1), 90 \mathrm{sec}(2), 105 \mathrm{sec}$ (1), and 120 sec (2). The first five shocks were given in one side and the remainder in the opposite side.

The barrier partitioning the shuttlebox was next raised, serving as the exteroceptive stimulus for the onset of the second (operant) component and allowing free responding between compartments.

The second component consisted of 30-min Sidman avoidance with an R-S interval of $20 \mathrm{sec}$, an $\mathrm{S}-\mathrm{S}$ interval of $5 \mathrm{sec}$, and $2-\mathrm{mA} .5-\mathrm{sec}$ shocks. Six 30-sec unreinforced CS presentations occurred at the start of the 5 th, 10th, $15 \mathrm{th}, 20 \mathrm{th}, 25 \mathrm{th}$, and 30 th $\mathrm{min}$ of the session. Two of these were CS, (light), two were $\mathrm{CS}_{2}$ (tone), and two were compounded (light and tone) in variable order such that one of each occurred in each half of the session. Only the data for the last 3 days are presented.

(2) Extinction was identical to Step 1 , except that the shocks were omitted in the first component. Data for the last 3 of the 7 days are included here.

(3) Avoidance was identical to the second component of Step 1, except that the CS presentations did not occur. This was continued twice a week for the first 3 weeks and five times the 4 th week.

(4) Spontaneous recovery began 1 month after the last extinction day and was identical to Step 1, except that the first component was omitted entirely. This continued for 3 consecutive days.

The measure used for calculating the conditioned inflection ratio was $\mathrm{CIR}=4 \mathrm{~B} /(\mathrm{A}+4 \mathrm{~B})$, where $\mathrm{A}=$ number of avoidances during the $2 \mathrm{~min}$ preceding CS onset and $B=$ number of CS avoidances.

\section{Results}

The results are presented in Fig. 2. As can be seen in the figure, all three Ss recovered to approximately their terminal acceleration ratios, with two Ss actually higher than during conditioning. Also, the two CSs in compound elicited higher ratios than the single stimuli in all nine test sessions. This is in agreement with results obtained with the same stimuli 


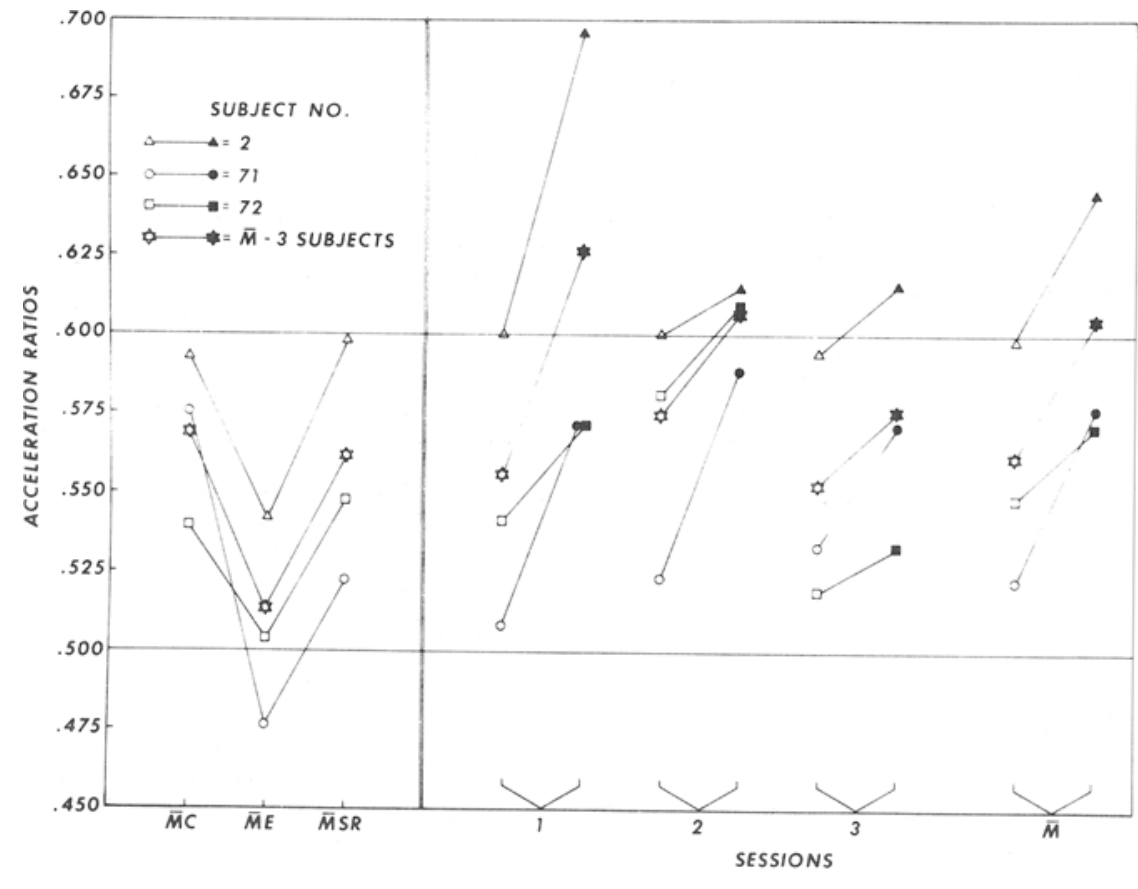

Fig. 2. Spontaneous recovery of conditioned acceleration shown in the left panel as means for single stimuli during (1) last 3 days of conditioning $(\overline{\mathrm{M}} \mathrm{C})$; (2) last 3 days of extinction ( $\bar{M} E)$; and (3) three days of spontaneous recovery (MSR). Right panel shows the differential recovery of single CSs (open figures) and the compound CS (solid figures) for single Ss by days.

during both conditioning and extinction (Riess, 1969).

DISCUSSION AND SUMMARY

There is a slight discrepancy between Experiments 1 and 2 in that recovery occurs to only about $50 \%$ of conditioning levels in Experiment 1 and to nearly $100 \%$ in Experiment 2 . Although it is tempting to attribute this difference to the fact that $S s$ in Experiment 1 had fewer reinforced Pavlovian trials and a shorter time from extinction to testing, major consideration must be given to the fact that $\mathrm{Ss}$ in Experiment 1 were tested only 3 days and the initial asymptotic performance during conditioning did not have sufficient time to level off before extinction began. The discrepancy in percentage recovery can
565 , regardless of CIR levels during extinction, or density of testing durin spontaneous recovery; (3) the the small levels obtained are very stubborn in terms of resistance to magnitude of recovery is modest, but extinction, with no apparent trend toward .500 in evidence in either study; and (4) when two separate CSs are employed in spontaneous recovery testing, they will elicit a greater $\mathrm{CR}$ in compound than when they are employed singly.

\section{REFERENCES}

ELLSON, D. G. Quantitative studies of the interaction of simple habits. I. Recovery from specific and generalized effects of extinction. Journal of Experimental Psychology, 1941, 23, 339-358.

HAYS, K. J. The backward curve: A method for the study of learning. Psychological Review, 1953, 60, 269-275.

HOFFMAN, H. S. FLESHLER M. \& JENSEN, $P$. Stimulus aspects of aversive controls: The retention of conditioned suppression. Journal of the Experimental Analysis of Behavior, 1963, 6, 575-583.

HOFFMAN, H. S., SELEKMAN, W., \& FLESHLER, M. Stimulus aspects of aversive controls: Long term effects of suppression procedures. Joumal of the Experimental Analysis of Behavior, 1966. 9, 659-662.

KIMBLE, G. A. Hilgard and Marquis' Conditioning and learning. New York: Appleton-Century-Crofts, 1961.

LEWIS, D. J. Acquisition, extinction, and spontaneous recovery as a function of percentage of reinforcement and intertrial intervals. Joumal of Experimental Psychology, 1956, 51, 45-53.

MARTIN, L. K., \& RIESS, D. Effects of US intensity during preliminary discrete delay conditioning on conditioned acceleration during avoidance extinction. Journal of Comparative \& Physiological Psychology, 1969, 69, 196-200.

PAVLOV, I. P. Conditioned reflexes. New York: Dover, 1960.

RIESS, D. Pavlovian phenomena in conditioned acceleration: Stimulus summation. Conditional Reflex, 1969, 4 . 257-264.

RIESS, D. Pavlovian phenomena in conditioned acceleration: Discrimination. Manuscript available from Galesburg(III.) State Research Hospital, 1970.

RIESS, D. \& BATH, J. Operant and Pavlovian stimulus control of avoidance latencies in conditioned acceleration. Psychonomic Science, 1970, 19, 165-167.

RIESS, D., \& MARTIN, L. K. Effects of UCS intensity during continuing coterminous delay conditioning on conditioned acceleration during maintained avoidance. Psychonomic Science, 1969, 16, 251.252.

WEISMAN, R. G., \& LITNER, J. S. The course of Pavlovian excitation and inhibition of fear in rats. Journal of Comparative \& Physiological Psychology, $1969,69,667-672$.
H UGHES, RONALD G. Response-reinforcement interactions in multiple interval schedules.-Psychon. Sci., 1971, 22 (5), p. 305. Title should read as follows: Responsereinforcement interactions in multiple-variable interval schedules.

BYRUM, RONALD P., and JACKSON, DONALD E. Response availability and second-order 